\title{
Satiation of mouse killing by rats in an operant situation*
}

\author{
PAUL E. VAN HEMEL† and JAMES S. MYER \\ The Johns Hopkins University, Baltimore, Md. 21218
}

Mouse-killing rats were allowed to pace their killing behavior by use of an operant response reinforced with mouse presentation. When tested after intervals of 1,2 , and 4 days without exposure to mice, the rats averaged more than 30 responses and kills before reaching a satiation criterion of $15 \mathrm{~min}$ without a response. In a $10-\mathrm{h}$ session, during which responding was continuously reinforced, four rats killed $32-57$ mice early in the session, then emitted occasional bursts of responses during the remainder of the session, obtaining and killing an average of 41 additional mice. These findings contradict a previous report that mouse killing by rats is easily satiated.

Mouse killing by rats is a very stable phenomenon. Rats that kill mice on a small number of selection tests continue to do so subsequently, even though no conventional reinforcer is-contingent upon the behavior (Myer, 1964). The opportunity to kill can serve as a teinforcer in instrumental learning situations (Myer \& White, 1965; Van Hemel, 1970), and killing latencies decrease with practice, suggesting that the behavior is reinforced by its own occurrence. The proposition that killing is self-strengthening is further supported by the observation that killing experience increases the resistance of the behavior to the suppressive effects of punishment (Myer, 1967). Punishment does suppress the behavior, but complete recovery usually occurs after punishment is discontinued (Myer \& Baenninger, 1966). These observations indicate that the killing response is quite reliable, an assumption that has been the basis of a number of experiments in which the suppression of the behavior has been ascribed to various manipulations, such as punishment (Myer \& Baenninger, 1966), pharmacological treatments_(Leaf, Lerner, \& Horovitz, 1969), or surgical manipulations (Karli; Vergnes, \& Didiergeorges, 1969).

Kulkarni (1968) has presented evidence that raises serious questions about previous assumptions concerning the stability of the killing response. Three groups of 12 mouse-killing rats were presented seven mice at intervals of 15,30 , or $60 \mathrm{~min}$. Six rats in the group tested at 15 -min intervals stopped killing during testing, as did three rats in the 30 -min intertrial-interval group and one rat in the group given hourly tests. Three of the rats which stopped killing also

\footnotetext{
* This research was supported by Grant GB8041 from the National Science Foundation to James S. Myer.

t Requests for reprints should be sent to Paul E. Van Hemel, Department of Psychology, University of Maine in Portland, $96 \mathrm{~F}$ almouth Street, Portland, Maine 04103.
}

failed to kill when given a single test the following day. The observation that the killing response wanes with repeated elicitation is not surprising in itself, for many "instinctive" or "consummatory" behaviors are subject to such short-term decrements (Hinde, 1966). It is surprising, however, that satiation effects appeared after so few responses and that recovery was incomplete the following day. Myer \& Baenninger (1966) presented 15 mice to mouse-killing rats at intervals of $30 \mathrm{~min}$ and found no increase in killing latencies or failures to kill. Myer (1968) found no response decrement in a large number of rats presented 5 mice at 30-min intervals. Van Hemel (1970) trained rats to press a key to obtain mice to kill, with a time-out period of $1 \mathrm{~min}$ after each response. At the end of training, rats permitted 10 reinforced responses each day responded almost immediately each time they were signaled that reinforcement was available.

The present study was conducted to analyze further the satiation of mouse-killing by rats. To maximize the Ss' control of the situation, they were permitted to perform an instrumental response to obtain mice, rather than being presented mice at arbitrarily selected intervals. Each response was reinforced by presentation of a mouse, continuing to a satiation criterion of failure to respond for $15 \mathrm{~min}$.

\section{APPARATUS}

The rats were trained and tested in four $205 \times 235 \times 190 \mathrm{~mm}$ high experimental chambers in an experimental room, illuminated by a $25-\mathrm{W}$ red light bulb, with white masking noise present throughout the study. A flat, transparent Plexiglas key was mounted flush with the outside of one end of each chamber over a 25 -mm-diam hole. Pressure greater than $5 \mathrm{~g}$ displaced the key $2.3 \mathrm{~mm}$, closing a circuit which activated programming and recording equipment in an adjacent room. Impulse counters recorded keypresses and printing counters, driven at 10 pulses/sec, recorded response latencies. A 36 -cm-diam motorized wheel with small wire mesh compartments delivered single mice to an opening $65 \mathrm{~mm}$ high and $75 \mathrm{~mm}$ wide in the side of the experimental chamber. A small light was mounted behind the transparent key and another behind the wheel at the opening to the chamber.

\section{PROCEDURE}

The Ss were selected from a group of 36 adult male Long-Evans rats, individually housed with continuous access to food and water. Three daily test presentations of a single mouse to each rat in its home cage identified 20 mouse-killing rats. On these and all subsequent tests, the bodies of killed mice were removed within $1 \mathrm{~min}$ of the kill. The 20 killers were presented three mice at 1-h intervals on each of the next 3 days and were placed in the experimental chambers for a 15 -min adaptation period after each day's testing. Five rats were discarded because they exhibited consistently long attack latencies, although they continued to attack every mouse presented. On each of the next 6 days of testing, the remaining 15 rats were given a $15 \cdot \mathrm{min}$ period of adaptation to the experimental chamber, after which a single mouse was presented through the opening in the side of the chamber. The light behind the wheel was turned on when the mouse was presented and remained on during the attack and kill. The same precedure was followed on the next 3 days, except that the adaptation period was

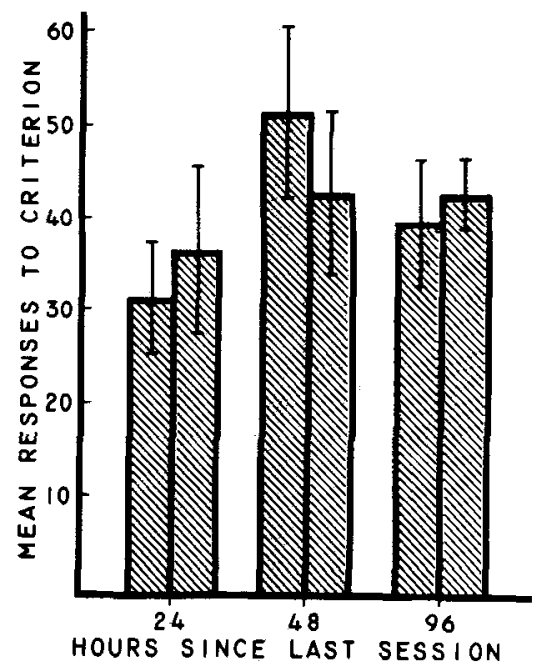

Fig. 1. Mean responses reinforced with mouse presentation during sessions conducted 1,2 , or 4 days after the preceding session and ended by a criterion of $15 \mathrm{~min}$ without a response. The standard errors of the means are shown as an indication of the variability. 
reduced to $5 \mathrm{~min}$. Eight rats which quickly and consistently killed mice throughout the pretesting period were selected for further study.

For the remainder of the experiment, daily sessions began with illumination of the key light. To allow time for the killing of the mouse and removal of its body, a 1 -min time-out followed each reinforcement. During the time-out periods the key light was extinguished, the light behind the opening through which the mice were presented was turned on, and responses were neither reinforced nor recorded. The bodies of killed mice were removed during the last $10 \mathrm{sec}$ of the time-out periods.

Shaping of the keypressing response was followed by up to 30 daily sessions in which each rat was permitted to press the key to obtain and kill mice five times. Another such session was conducted 2 days after the last of these training session. Two days later a "satiation" session was conducted, in which all responses were reinforced until a "satiation" criterion of $15 \mathrm{~min}$ without a response was reached. This initial satiation session was followed by two additional sessions at 2-day intervals, two at 1-day intervals, and two at 4-day intervals, in that order. Thus there were three pairs of satiation sessions which followed recovery intervals of 1,2 , and 4 days. To determine the pattern of responding during a more prolonged period, on the last session the second squad of four rats was left in the experimental chambers for $10 \mathrm{~h}$.

\section{RESULTS AND DISCUSSION}

The mean numbers of responses to the criterion of $15 \mathrm{~min}$ without a response in each of the six sessions are shown in Fig. 1. $t$ tests revealed no significant differences in number of responses as a function of days since the preceding satiation session or between the two tests at each interval. Response latency, the time which elapsed from the illumination of the key light at the end of each time-out until the occurrence of the next response, averaged
43,56 , and $47 \mathrm{sec}$ for the tests conducted after periods of 1, 2, and 4 days, respectively.

The four rats given a 10 -h session in the apparatus reached the satiation criterion of $15 \mathrm{~min}$ without a response after 47-144 min, during which they obtained and killed $32-57$ mice. During the subsequent period they averaged 41 more responses and kills, responding in "bouts" in which they would obtain several mice in rapid succession, followed by long intervals during which $\mathrm{ni}$ onse occurred. The appropriateness or ine satiation criterion of $15 \mathrm{~min}$ without a response is indicated by comparison of the distribution of response latencies of less than $15 \mathrm{~min}$ with distribution of longer latencies during the 10 h session. Latencies of less than $15 \mathrm{~min}$ averaged $90.5 \mathrm{sec}$, and the mean of the distribution of latencies greater than $15 \mathrm{~min}$ was $87 \mathrm{~min}$. Thus, failure to respond during a 15 -min period generally indicated the beginning of a fairly prolonged pause. During the $10-\mathrm{h}$ session the rats were observed to sleep most of the time during the long pauses and to feed, drink, groom themselves, and respond for mice periodically. These observations suggest that if the opportunity to respond for mice were continually available, mouse-killing would be synchronized with the correlated activity cycles characteristic of other behaviors of the rat (Bolles, 1960).

The findings of the present study are not consistent with Kulkarni's report that the mouse-killing response of rats is easily satiated. In a situation where the rats could respond to obtain and kill mice or could avoid contact with mice simply by not responding, the rats in the present experiment killed substantial numbers of mice before pausing for as long as $15 \mathrm{~min}$ and displayed complete recovery from "satiation" after intervals as short as $24 \mathrm{~h}$. In none of the test sessions of the present study did the mean number of responses fall below 30, and in all but one of them the mean was greater than 35 . It is interesting that these values compare favorably with the finding that rats will kill as many as 30 frogs in rapid succession (Huston, De Sisto, \& Meyer, 1969). The present results, combined with the observations from previous experiments cited above, indicate that mouse-killing by rats is considerably more persistent than Kulkarni’s (1968) report suggests.

\section{REFERENCES}

BOLLES, R. C. Grooming behavior in the rat. Journal of Comparative \& Physiological Psychology, 1960, S3, 306-310.

HINDE, R. A. Animal behavior. New York: McGraw-Hill, 1966.

HUSTON, J. P., DeSISTO, M. J., \& MEYER, E. P. Frog-killing by rats as influenced by territorial variables. Paper presented at the meeting of the Eastern Psychological A ssociation, Philadelphia, April 1969.

K ARLI, P., VERGNES, M., \& DIDIERGEORGES, F. Rat-mouse interspecific aggressive behavior and its manipulation by brain ablation and brain stimulation. In E. B. Sigg and S. Garattini (Eds.), Biology of aggressive behavior. Amsterdam: Excerpta Medica Foundation, 1969. Pp. 47-55.

KULKARNI, A. S. Satiation of instinctive mouse-killing by rats. The Psychological Record, 1968, 18, 385-388.

LEAF, R. C., LERNER, L., \& HOROVITZ, Z. P. The role of the amygdala in the pharmacological and endocrinological manipulation of aggression. In E. B. Sigg and S. Garattini (Eds.), Biology of aggressive behavior. Amsterdam: Excerpta Medica Foundation, 1969. Pp. 120-131.

MYER, J. S. Stimulus control of mouse-killing rats. Journal of Comparative \& Physiological Psychology, 1964, 58, 112-117.

MYER, J. S. Prior killing experience and the effects of punishment on the killing of mice by rats. Animal Behaviour, 1967, 15, 59-61.

MYER, J, S. Associative and temporal determinants of the facilitation and inhibition of attack by pain. Journal of Comparative \& Physiological Psychology, 1968, 66, 17-21.

MYER, J. S., \& BAENNINGER, R. Some effects of punishment and stress on mouse-killing by rats. Journal of Comparative \& Physiological Psychology, 1966, 62, 292-297.

MYER, J. S., \& WHITE, R. T. Aggressive motivation in the rat. Animal Behaviour, 1965 , 13, 430-433.

Van HEMEL, P. E. Aggression as an incentive: Operant behavior in the mouse-killing rat. Unpublished doctoral dissertation, Johns Hopkins University, 1970. 